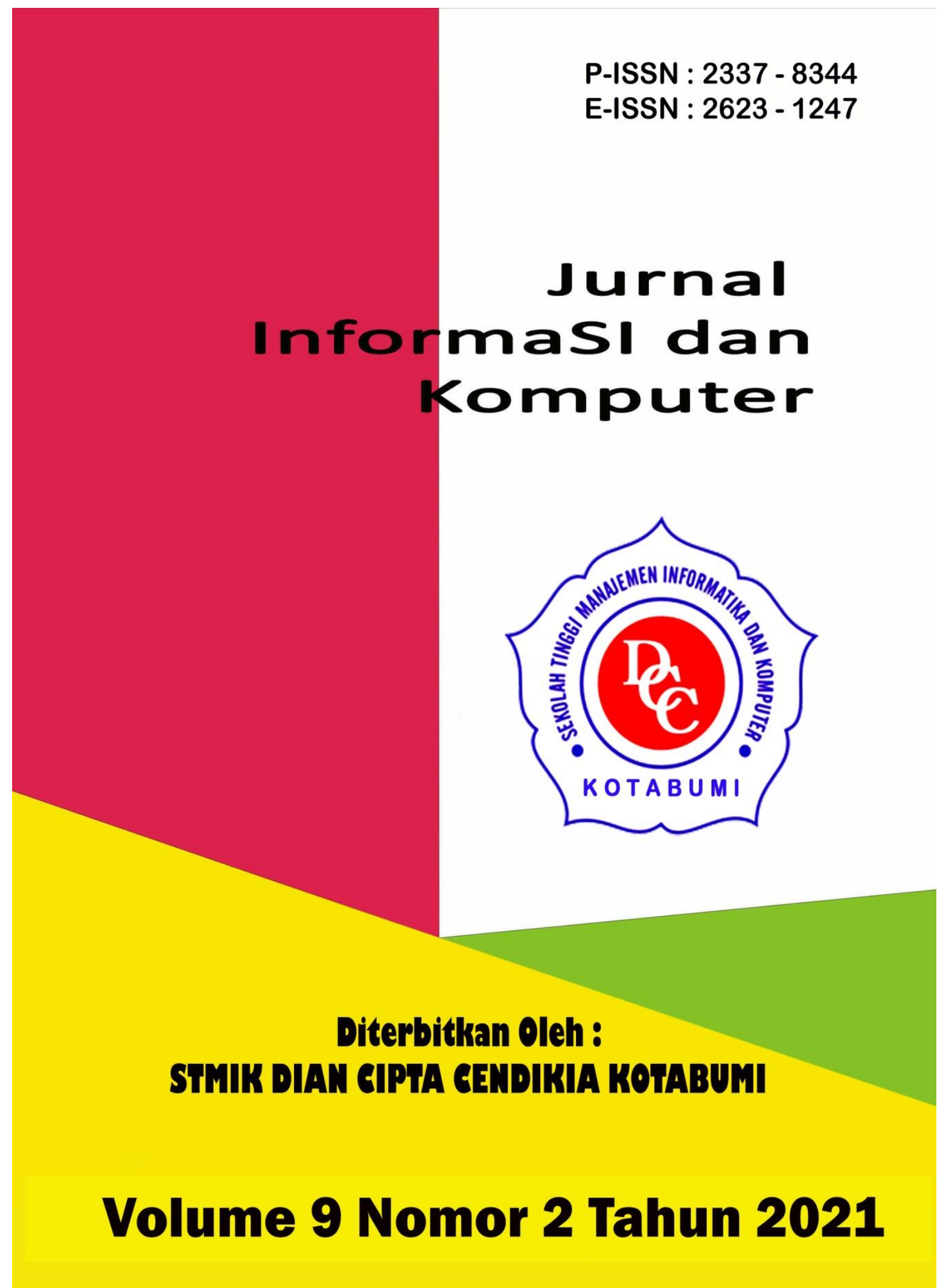




\section{Penerbit}

\section{Lembaga Penelitian STMIK Dian Cipta Cendikia Kotabumi}

Hak atas naskahh/tulisan tetap berada pada penulis, isi diluar tangung jawab penerbit dan Dewan Penyunting 


\section{PENGANTAR REDAKSI}

Puji syukur dipanjatkan kehadirat Tuhan Yang Maha Esa, atas karunia dan limpahan rahmatNYA jualah Jurnal Informasi dan komputer (JIK) STMIK Dian Cipta Cendikia Kotabumi ini dapat terwujud.Jurnal Informasi dan Komputer (JIK) yang terbit dua (2) kali dalam setahun ini merupakan suatu wadah untuk penyebar luasan hasil-hasil penelitian, studi pustaka, karya ilmiah yang berkaitan dengan Informasi dan Komputer khususnya bagi dosen-dosen STMIK Dian Cipta Cendikia Kotabumi serta umumnya para cendikiawan, praktisi, peneliti ilmu Informatika dan Komputer.

Harapan, dengan diterbitkannya Jurnal Informasi dan Komputer (JIK) ini sebagai salah satu bentuk sumbangan pemikiran dalam pengembangan ilmu informatika dan komputer yang berkaitan dengan kajian-kajian di bidang tekhnologi Informatik, Komunikasi Data dan Jaringan Komputer, perancangan dan Rekayasa Perangkat Lunak, serta ilmu-ilmu yang terkait dengan bidang Informasi dan Komputer lainnya.

Berkenaan dengan harapan tersebut, kepada para peneliti, dosen dan praktisi yang memiliki hasil-hasil penelitian, kajian pustaka, karya ilmiah dalam bidang tersebut diatas, dengan bangga redaksi Jurnal Informasi dan Komputer (JIK) menerima naskah ringkasan untuk dimuat pada jurnal Informasi dan Komputer (JIK) STMIK Dian Cipta Cendikia Kotabumi dengan berpedoman pada penulisan naskah jurnal sebagaimana dilampirkan pada halaman belakang (Bagian kulit dalam) buku jurnal ini.

Mutu dari suatu jurnal ilmiah tidak hanya ditentukan oleh para pengelolanya saja, tetapi para penulis dan pembaca jualah yang mempunyai peranan besar dalam meningkatkan mutu jurnal Informatika dan Komputer ini. Merujuk pada realita ini kamu sangat mengharapkan peran aktif dari peneliti untuk bersama-sama menjaga dan memelihara keberlangsungan dari jurnal Informasi dan Komputer STMIK Dian Cipta Cendikia Kotabumi ini. Yang juga tidak kalah pentingnya dari partisipasi tersebut diatas, adalah saran dan kritik yang membangun dari pembaca yang budiman agar kiranya dapat disampaikan langsung kepada redaksi JIK. Saran dan kritik yang membangun akan dijadikan masukan dan pertimbangan yang sangat berarti guna peningkatan mutu dan kualitas Jurnal Informasi dan Komputer STMIK Dian Cipta Cendikia Kotabumi.

Tak lupa diucapkan terima kasih yang tak terhingga atas perhatian dan kerjasama dari semua pihak yang tak dapat disebutkan satu persatu hingga dapat diterbitkan nya Jurnal Informasi dan Komputer (JIK) STMIK Dian Cipta Cendikia Kotabumi. Semoga apa yang telah diperbuat untuk kebaikan akan menjadi amal ibadah, amin.

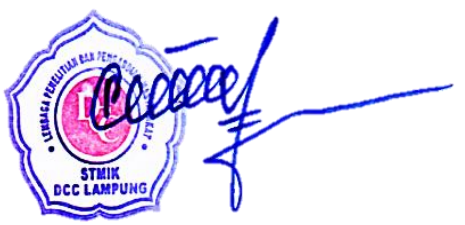

Dewan Redaksi 


\section{JURNAL INFORMASI DAN KOMPUTER}

Volume 9 Nomor 2 Oktober 2021

Jurnal Informasi dan Komputer merupakan Sarana informasi ilmu pengetahuan, Tekhnologi dan Komunikasi yang berupa hasil penelitian, tulisan ilmiah, Ataupun studi pustaka. Jurnal ini terbit dua kali setahun pada bulan April dan Oktober. Berisi hasil penelitian ilmiah di bidang informatika yang bertujuan untuk menghubungkan adanya kesenjangan antar kemajuan teknologi dan hasil penelitian. Jurnal ini di terbitkan pertama kali pada tahun 2013.

Penanggung Jawab:

Ketua STMIK Dian Cipta Cendikia Kotabumi

\section{Pembina:}

Ketua STMIK Dian Cipta Cendikia Kotabumi Ketua Lembaga Penelitian STMIK Dian Cipta Cendikia Kotabumi

\section{Pimpinan Redaksi}

Dwi Marisa Efendi,.S.Kom.,M.Ti

\section{Redaksi pelaksana}

Rustam,.S.Kom,.M.Ti (STMIK Dian Cipta Cendikia Kotabumi)

Nurmayanti M.Kom (STMIK Dian Cipta Cendikia Kotabumi)

Sukatmi,.S.Kom., M.Kom (AMIK DCC Bandar Lampung)

Sampurna Dadi Riskiono,M.Kom (Universitas Teknokrat Indonesia)

Ifo Wahyu Pratama,S.Kom.,M.Ti(AMIK MASTER Lampung)

\section{Mitra Bestari}

Dr. RZ. ABDUL AZIZ, ST., MT (Institut Informatika dan Bisnis Darmajaya)

Dr. Dadang Sudrajat, S.Si, M.Kom (STMIK IKMI Cirebon)

Dr. Septafiansyah Dwi Putra, S.T., M.T (Politeknik Negeri Lampung)

Dr. Evi Grativiani, S.E., M.S.I (Universitas Sebelas Maret)

Rohmat Indra Borman ( Universitas Teknokrat Indonesia )

Ferry Wongso, S.KOm., M.Kom ( STMIK Darma Pala Riau)

Ferly Ardhy, S.Kom., M.Ti ( Universitas Aisyah Pringsewu )

Firmansyah, S.E., M.Si (STMIK Darma Pala Riau)
Amarudin (Universitas Teknokrat Indonesia)

Didi Susianto, S.T., M.Kom (AMIK Dian Cipta Cendika Bandar Lampung)

Alhibarsyah, St., M.Kom (STMIK Tunas

Bangsa Bandar Lampung)

Kemal Farouq Mauladi, S.Kom .M.Kom (Universitas Islam Lamongan)

Rima Mawarni, M.Kom ( STMIK Dian Cipta Cendikia Kotabumi)

Wira Jaya Hartono, S.Pd., M.Pd ( STMIK Darma Pala Riau)

Penerbit : STMIK Dian Cipta Cendikia Kotabumi Bekerja Sama Dengan LPPM STMIK Dian Cipta Cendikia Kotabumi.

\section{Alamat Redaksi/Penerbit:}

Jl. Negara No. 3 Candimas Kotabumi Lampung Utara

No Telpon/Fax 072423003

Email : 1ppm-stmik@dcc.ac.id 


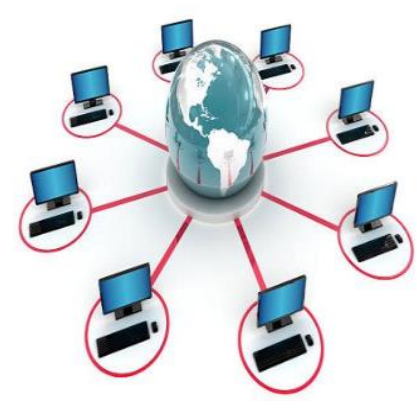

\section{JURNAL INFORMASI DAN KOMPUTER VOL. 9 NO. 2 THN. 2021}

\section{DAFTAR ISI}

Halaman

Sistem Informasi Akuntansi Persedian Barang Berbasis Web Pada Lembaga

Permasyarakatan Kelas II A Banceuy Bandung : "Kelompok Tani Desa Banjar Kertarahayu” Teuku Rian Hardiyansyah, Fatia Salsa Azzahra (Politeknik Piksi Ganesha Bandung ${ }^{1,2}$ ).

Penerapan Finite State Automata Pada Vending Machine Penjual Obat Non Resep

Dokter Dan Keperluan Medis

Eko Supriyanto $^{1}$, Angga Ardiansyah ${ }^{2}$, Frieyadie $^{3}$, Sri Rahayu ${ }^{4}$, Windu Gata ${ }^{5}$

(Universitas Nusa Mandiri ${ }^{12}$ )

Sistem Pendukung Keputusan Untuk Menentukan Kelayakan Pengajuan Sertifikasi Guru Dengan Metode Simple Additive Weighting (Studi Kasus : Ma Al Muhajirin Janti Jogoroto Jombang)

Budiman, umam baharudin, winarti

(Universitas Darul 'Ulum Jombang)

Perancangan Infrastruktur Domain Name Server Lokal Menggunakan Ubuntu Server 16.04

Pada PT. Xyz

Zaenal Mutaqin Subekti, Hendra Setiawan, Satria, Widia Murni Wijaya,

Aliy Hafiz, Warsudi

(STMIK Bani Saleh, Universitas Negeri Yogyakarta, AMIK Dian Cipta Cendikia,

STMIK MIC CIkarang)

Perancangan Sistem Informasi Idea Proposal (Ip) Berbasis Web Pada Pt. Paxel Algorita Unggul

Julian Murhan Sahputra, Indah Purnamasari

(Universitas Nusa Mandiri ${ }^{12}$ )

Sistem Pendukung Keputusan Untuk Menentukan Ekstrakurikuler Atletik

Berdasarkan Bakat Siswa Menggunakan Metode Profile Matching

Agnes Basuki, Petrus Sokibi, Tiara Eka Putri

(Universitas Catur Insan Cendekia)

Penerapan Algoritma K-Means Untuk Pengelompokan Usia Calon Penerima Vaksin

Di Kab. Ngawi

Irna Yuniarfi, Saifulloh

(Universitas PGRI Madiun $^{12}$ )

System Penilaian Seleksi Calon Karyawan Baru Menggunakan Metode Simple Additive Weighting (SAW) Di PT.TNA

Anik Sri Wahyuningsih, Yudhi Firmansyah

(Universitas Panca Sakti Bekasi )

Perancangan Sistem Informasi Pembayaran SPP Menggunakan Framework Laravel 
Ichwan Habib Moudi

(Universitas Panca Sakti Bekasi) $75-80$

Implementasi Algoritma K-Means Dan Algoritma Apriori Optimasi Kinerja Ecu

(Study Kasus Mobil Avanza Dan Xenia)

Sigit Mintoro' Asep Afandi

(STMIK Dian Cipta Cendikia Kotabumi)

Sistem Pakar Penyakit Buah Kakao Untuk Peningkatan Hasil Panen Kakao Menggunakan

Metode Case Base Reasoning (CBR) Berbasis Web Mobile

Aliy hafiz, Verawati

(AMIK Dian Cipta Cendikia,Bandar Lampung)

Penerapan Metode Rapid Application Develomment (RAD) Dalam Pengembangan

Sistem Pemesanan Menu Berbasis Android

Aris Baihaqi, Tumini

(Fakultas Sains dan Teknologi ${ }^{1,2}$ )

Rancang Bangun Sistem Informasi Geografis Pariwisata Di Lampung Timur

Sukatmi, Rexa Alfa Rizi

(AMIK DCC Bandar Lampung ${ }^{12}$ )

Implementasi Psak No. 45 Pada Proses Penyusunan Laporan Keuangan Menggunakan

M.S. Excel Dan Aplikasi Accurate Accouting Pada STMIK Bani Saleh

Marhakim, Willy Adam

(STMIK Bani Saleh ${ }^{12}$ )

Sistem Prediksi Harga KOPI LAMBAR ( Lampung Barat) Dengan Metode

Backpropagation, dan Double Exponential ( Studi Kasus BUMDES )

Supriyanto, Dwi marisa Efendi,Rhomadhon

(STMIK Dian Cipta cendikia Kotabumi ${ }^{1-}$ )

Sistem Informasi Pemasaran Produk Umkm Berbasis Web Pada Kecamatan Bumi

Nabung Lampung Tengah

Yuli Syafitri, Agus Prasetyo, Reni Astika

(AMIK Dian Cipta Cendikia Bandar Lampung)

Rancang Bangun Aplikasi Pembelajaran Aksara Lampung Berbasis Android

Ferly Ardhy, Hendra Syahrobi

(Universitas Aisyah Pringewu ${ }^{1,}$ STMIK Dian Cipta Cendikia ${ }^{2}$ )

Sistem Pakar Diagnosa Penyakit Kulit Pada Balita Menggunakan Metode Naïve

Bayes Dan Forward Chaining Studi Kasus Puskesmas Cempaka Sungkai Selatan

Sidik Rahmatullah, Rima Mawarni

(STMIK Dian Cipta Cendikia Kotabumi ${ }^{12}$ )

Rekayasa Perangkat Lunak Perhitungan Harga Pokok Produksi Metode

Full Costing Pada Umkm Mitra Cake Di Bandar Lampung

Pitrawati, Arif Sanjaya

(AMIK Dian Cipta Cendikia, Bandar Lampung)

Rancang Bangun Sistem Ujian Online Menggunakan Algoritma Cosine Similarity

Berbasis Web

Haryono, Zaenal Mutaqin Subekti, Widiyawati, Hidayatullah

(STMIK Bani Saleh $^{1234}$ ) $163-168$ 
Model Aplikasi Helpdesk Ticketing System Berbasis Web Menggunakan Metode Rad Indra Permana

Pattern Recognition Tulisan Tangan Huruf Hijaiyah Menggunakan Metode Convolutional Neural Network (CNN)

Mufassiril Abror, Nopiyanto

(Universitas Panca Sakti Bekasi ${ }^{12}$ )

Aplikasi Sistem Informasi Keuangan Berbasis Android Di Perumahan Taman

Karang Bahagia

Melda Ayulestari

(Universitas Panca Sakti Bekasi)

Audit Pelayanan Sistem Rujukan Online Puskesmas Menggunakan Framework COBIT 5.0

Nurmayanti, Merri Parida, Ngajiyanto, Ina Anzalna

(STMIK Dian Cipta Cendikia Kotabumi ${ }^{1234}$ )

Perancangan Sistem Informasi Pengolahan Data Nilai Siswa Berbasis Web

Erin Ermawati, Anik Sri Wahyuningsih

(Fakultas Sain dan Teknologi, Universitas Panca Sakti Bekasi ${ }^{12}$ )

Pengembangan Sistem Pelaporan Data Hasil Inspeksi Barang Berbasis Web

Siska Putriani

(Universitas Pancasakti Bekasi)

Penerapan Extreme Programming Dalam Perancangan Aplikasi Web Food Market

Tumini, Hilman Septiana

(Fakultas Sains dan Teknologi Universitas Panca Sakti Bekasi ${ }^{1,2}$ )

Sistem Pencarian Barang Berbasis Website Menggunakan Php Dan Mysql

Studi Kasus PT. Surya Technology Industri

Sulaeman

(Universitas Panca Sakti Bekasi)

Implementasi Metode Prototype Pada Sistem Peminjaman Alat Kerja Berbasis Web

Di PT SK Metalindo

Ali Mulyanto, Arjun Gunawan

(Univeritas Panca Sakti Bekasi)

Aplikasi Tata Cara Wudhu Menggunakan Teknologi Augmented Reality

Sebagai Media Pembelajaran

Di TK Al Fatih

Ahmad Yakub, Idarul Fadli

(Universitas Panca Sakti Bekasi ${ }^{12}$ )

Sistem Pakar Diagnosa Penyakit Ayam Petelur Menggunakan Metode Certainty Factor

Berbasis Web

Mochammad Taufiq Hidayat, Ali Mulyanto

(Universitas Panca Sakti Bekasi ${ }^{12}$ )

Penerapan Metode Prototyping Dalam Perhitungan Hasil Produksi Menggunakan

Arduino Uno R3 Dan Php Di PT. Indonesia Epson Industry

Amandha Aulia, Ajar Rohmanu

(Universitas Panca Sakti Bekasi ${ }^{12}$ ) 
System Pendukung Keputusan Penentuan Guru Teladan Dengan Metode Profile Matching

Hasbulloh, Agmawarnida

(Universitas Panca Sakti Bekasi ${ }^{1,2}$ )

Implementasi Waterfall Method Pada Aplikasi Buku Induk Siswa Berbasis Web

Idam Holid, Yogie Krisnayadi

(Universitas Panca Sakti ${ }^{12}$ )

Pengembangan Text To Speech Media Pembelajaran Untuk Pengenalan

Anggota Tubuh Manusia Kelas V Sekolah Dasar

Juwanda Saputra, Ali Mulianto

(Teknik Infomratika Fakulutas Sains dan Teknologi ${ }^{12}$ )

Perancangan Sistem Peminjaman Barang Berupa Aset Tetap Berbasis Web

Pada Lembaga Permasyarakatan Kelas II A Banceuy Bandung

Guntur Salasa Priambodo, Perwito, Candra Mecca Sufyana

(Politeknik Piksi Ganesha Bandung ${ }^{1,2,3}$ )

Metode Pemilihan Karyawan Terbaik Sebagai Penentu Goodwill Perguruan Tinggi

Dengan Menggunakan Metode Topsis (Studi Kasus Perguruan Tinggi Di Lampung Utara)

Dwi Sartika, Pakarti Riswanto

(STMIK Dian Cipta Cendikia Kotabumi)

Sistem Pendukung Keputusan Pemilihan Merek Smartphone Menggunakan

Metode Analytical Hierarchy Process (AHP)

Ade Kiki Fatmawati, Muhammad Sultan Raflie, Norma Yunita

(Universitas Nusa Mandiri ${ }^{123}$ )

Pattern Recognition Aksara Lampung Menggunakan Algoritma Neural Network

Metode Analytical Hierarchy Process (AHP)

Nopiyanto, Rahmadi

(Universitas Panca Sakti Bekasi) 


\title{
SISTEM INFORMASI AKUNTANSI PERSEDIAN BARANG BERBASIS WEB PADA LEMBAGA PERMASYARAKATAN KELAS II A BANCEUY BANDUNG
}

\author{
Teuku Rian Hardiyansyah ${ }^{1}$, Fatia Salsa Azzahra ${ }^{2}$ \\ Politeknik Piksi Ganesha Bandung ${ }^{1,2}$ \\ Jl. Gatot Subroto No.301, Maleer, Kec. Batununggal, Kota Bandung, Jawa Barat ${ }^{1,2}$ \\ E-mail: Teukurianh1998@gmail.com ${ }^{1}$, fatiasalsa58@gmail.com ${ }^{2}$
}

\begin{abstract}
ABSTRAK
Permasalahan yang dihadapi oleh Lembaga Permasyarakatan Kelas II A Banceuy Bandung yaitu permintaan barang yang dilaksanakan oleh staff masih dilakukan secara manual dan sering menimbulkan suatu masalah, permasalahannya adalah setiap staff dapat melakukan permintaan barang ke bagian sapras tanpa ada batasan, hal ini menyebabkan aktivitas permintaan barang tidak terpantau, dan menyebabkan stok barang yang ada di gudang habis. Tujuan penelitian ini dilakukan yaitu untuk memudahkan proses permintaan barang dan persedian barang Penjara Banceuy dengan membuat Sistem Informasi akuntansi Persediaan Barang Berbasis Web, dengan memakai metode penelitian waterfall. Untuk mendapatkan informasi dan data yang diperlukan digunakan wawancara sebagai metode pengumpulan data. Lalu merancang database dan UI, dan selanjutnya melakukan proses coding dengan dengan bahasa pemrograman PHP dan MySQL untuk membuat database. Sistem Informasi Akuntansi Persedian Barang yang diciptakan akan memiliki fitur untuk melihat data persediaan barang, peginputan barang masuk, penginputan barang keluar. Kebutuhan fungsional sistem ini telah teruji, dan proses-prosesnya sudah sesuai dengan proses bisnis yang ada di Lembaga Permasyarakatan Kelas II A Banceuy Bandung. Sistem tersebut membantu agar proses permintaan barang dapat dilakukan dengan mudah oleh staff penjara banceuy dan juga dapat melihat data persediaan barang., sehingga kinerja dan pelayanan yang dirasakan oleh staff menjadi maksimal.
\end{abstract}

Kata Kunci: Lembaga Permasyarakatan Kelas II A Banceuy Bandung, Persediaan Barang, Peracangan Sistem

\section{ABSTRACTS}

The problem faced by the Class II A Banceuy Bandung Penitentiary is that the request for goods carried out by the staff is still done manually and often causes a problem, the problem is that each staff can request goods to the sapras section without any restrictions, this causes the activity of requesting goods not monitored, and causes the stock of goods in the warehouse to run out. The purpose of this research is to facilitate the process of requesting goods and supplies of Banceuy Prison goods by creating a WebBased Inventory Accounting Information System, using the waterfall research method. To obtain the necessary information and data, interviews were used as a data collection method. Then design the database and UI, and then do the coding process with the PHP and MySQL programming languages to create a database. The inventory accounting information system created will have features to view inventory data, input goods in, input goods out. The functional requirements of this system have been tested, and the processes are in accordance with the existing business processes at the Class II A Banceuy Penitentiary Bandung. The system helps so that the process of requesting goods can be carried out easily by Banceuy prison staff and can also view inventory data, so that the performance and service felt by the staff are maximized.

Keywords: Penitentiary Class II A Banceuy Bandung, Inventory, System Design

\section{PENDAHULUAN}

Lembaga Permasyarakatan kelas II A Banceuy dibangun oleh Belanda pada tahun 1877, yang pada awalnya penjara dikhususkan untuk kriminal dan tahanan politik tingkat rendah. Berdasarkan Surat Menteri Kehakiman RI No. W8.UM.01.06.245 A tanggal 30 September 1999 tentang Pembentukan Lapas Khusus Napi 
Narkoba Penjara Banceuy diperuntukan menampung narapidana kasus narkotika dari Kantor Wilayah Departemen Kehakiman DKI Jakarta dan Jawa BaratPenjara Banceuy berlokasi di Jalan Soekarno Hatta No. 187A Bandung, sebelumnya terletak di jalan Banceuy No. 8 Bandung.

Dalam struktur organisasi Lembaga Permasyarakatan kelas II A Banceuy terdapat bagian sapras yang bertugas atas persediaan barang dalam lingkup Lembaga Permasyarakatan kelas II A Banceuy. Sekarang, permintaan barang yang dilaksanakan oleh pegawai kepada bagian sapras dilakukan manual atau hanya lisan saja, sehingga sering terjadi kehabisan barang yang diminta, padahal barang akan digunakan segera. Akibatnya, para staff sering memakai uang pribadi dan nanti uangnya akan diganti yang mana prosesnya lama dan rumit. Perkembangan teknologi saat ini sangat canggih, kehidupan sekarang yang dipenuhi dengan teknologi yang terus berkembang sehingga kita berada dizaman yang dikenal modern. Jika tidak ada sistem informasi akuntansi, dampaknya proses bisnis menjadi tidak maksimal. Oleh karenanya, berdasarkan permasalahan yang dihadapi, dengan merancang dan membangun sebuah sistem informasi akuntansi dapat jadi solusi masalah yang dihadapi.

Sistem informasi akuntansi memiliki peran dalam memproses input-output persediaan barang, sehingga bisa membantu kegiatan permintaan barang dibagian sapras Lembaga Permasyarakatan kelas II A Banceuy khususnya pada pengelolaan persedian barang. Sistem informasi akuntansi persedian barang dikembangkan dengan berbasis web dengan alasan dan berbagai hal yang sangat mendukung, contohnya fasilitas yang sesuai untuk penerapan sistem informasi akuntansi berbasis web, salah satunya $P C$ berbrowser dan adanya PC server internal yang terhubung ke setiap $P C$ staff Dengan begitu staff hanya tinggal mengakses alamat website yang telah diberikan untuk menggunakannya dan tidak perlu memasang aplikasi desktop dahulu.

\section{METODE PENELITIAN}

\subsection{Informasi}

menurut Anggreani dan Irviani dalam jurnal Usdedi (2020) "informasi adalah sekumpulan data yang di organisme atau diolah dengan cara tertentu sehingga mempunyai arti bagi penerima. Data yang telah diolah menjadi sesuatu yang berguna bagi penerima yang dapat memberikan keterangan atau pengetahuan".

Menurut Romney dan Steinbart dalam jurnal Usdedi (2020) "informasi adalah data yang telah dikelola dan diproses untuk memberikan arti memperbaiki proses pengambilan keputusan".

\subsection{Sistem}

menurut Maniah dan Dini dalam jurnal Usdedi (2020) "Sistem adalah sekumpulan dari elemen - elemen baik itu berupa data, jaringan kerja dari prosedur, sumber daya manusia, serta teknologi baik perangkat keras (hardware) maupun perangkat lunak (software) yang saling berhubungan sebagai salah satu kesatuan untuk mencapai tujuan atau sasaran tertentu yang sama".

\subsection{Sistem Informasi}

Rizki, Priadi \& Yuniati dalam jurnal Usdedi (2020) mengatakan "sistem informasi merupakan gabungan dari manusia, alat teknologi, media, prosedur, dan pengendalian yang berguna untuk menata jaringan komunikasi yang penting. Proses atas transaksitransaksi tertentu dan rutin, membantu manajemen dalam menyediakan dasar pengambilan dasar pengambilan keputusan yang tepat".

\subsection{Akuntansi}

Akuntansi adalah suatu sistem informasi yang meliputi proses mengidentifikasi, mengukur dan melaporkan informasi ekonomi dan mengkomunikasikan hasilnya dalam bentuk laporan keuangan diiformasikan kepada pengguna laporan keuangan untuk dijadikan sebagai pertimbangan pengambilan keputusan.

\subsection{Web}

menurut Rohi Abdulloh dalam jurnal Usdedi (2020) "web adalah sekumpulan halaman yang terdiri dari beberapa halaman yang berisi informasi dalam bentuk data digital baik berupa teks, gambar, video, audio dan animasi lainnya yang disediakan melalui jalur koneksi internet". 


\subsection{Persediaan}

menurut Sigit Hermawan dalam jurnal (Usdedi, 2020) "persediaan merupakan barang dagangan yang disimpan kemudian dijual kembali dalam operasional normal perusahaan dan bahan yang terdapat dalam proses produksi atau yang telah disimpan untuk suatu tujuan".

\subsection{Kerangka Kerja Penelitian}

Penelitian dilaksanakan berdasarkan tahapan kegiatan. Tahapan kegiatan terserbut adalah cara agar tercapainya tujuan penelitian. Tahapan kegiatan tersebut digambarkan sebagai berikut:

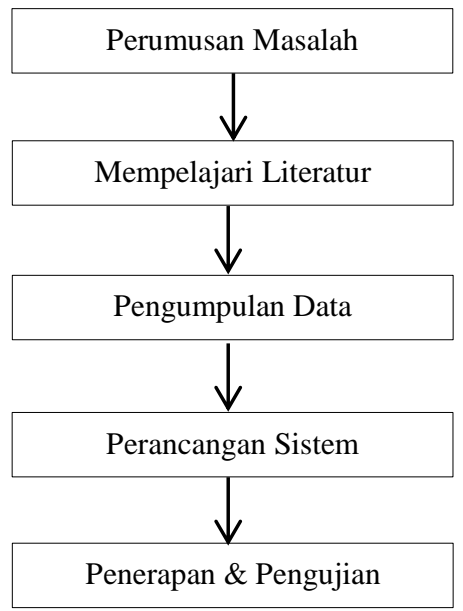

Gambar 1. Kerangka Kerja Penelitian

Bagian ini berisi tetang metode waterfall. gambar metode penelitian dapat dilihat digambar berikut :

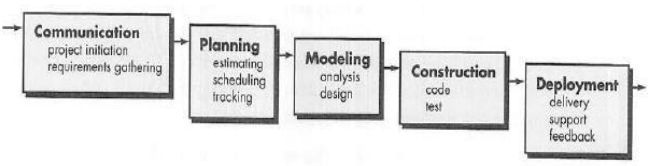

Gambar 2. Metode Waterfall

\subsection{Communication}

disini penulis mengumpulkan data dan observasi masalah yang ada di Penjara Banceuy, untuk mendapatkan data dari penjara banceuy penulis melakukan wawancara dan observasi kepada Penjara Banceuy.

\subsection{Planning}

Tahap planning adalah proses selanjutnya. Pada bagian ini dijelaskan tentang waktu dan periode penelitian yang akan dilaksanakan, jadwal penelitian yang akan dilaksanakan, dan proses pelacakan pembuatan sistem informasi akuntansi ini.

\subsection{Modelling}

Setelah communication dan sudah didapat data yang benar dan mendapat hasil dari analisis masalah yang terjadi di Penjara Banceuy, selanjutnya adalah modelling memproses data yang telah didapatkan dan diproses untuk melakukan perancangan sistem yang selanjutnya akan diciptakan.

\subsection{Construction}

Tahap ini adalah proses penerapan kode.. Programmer akan menjadi penerjemah perintah yang diberikan oleh user kepada bahasa yang dapat dikenali komputer. Bagian ini adalah bagian penciptaan sistem, yang mana peggunaan komputer akan jadi maksimal dalam bagian ini. Selesai pengodean lalu akan dilakukan pengertesan pada sistem yang sudah dibuat. Tujuan dari pengetesan ini adalah untuk menemukan bug / error pada sistem yang telah dibuat yang nantinya bisa diperbaiki sehingga siap untuk diterapkan.

\subsection{Deployment}

Tahap ini adalah tahapan terakhir pada pembuatan sistem, sesudah dilakukan analisis, desain, dan pembuatan kode maka sistem telah siap untuk memasuki tahapan penerapan sistem pada user dan menyerahkan hasilnya pada user. Bagian fungsi sistem melakukan pengujian sistem dari user. Lalu sistem yang sudah dibuat akan ditest dan dilaksanakan maintenance dengan rutin serta mendapat saran dan masukan dari user untuk system depelovement.

\subsection{Lokasi Penelitian}

Kegiatan penelitian ini berlokasi di Lembaga Permasyarakatan Kelas II A Banceuy Bandung.

\section{HASIL DAN PEMBAHASAN}

\subsection{Communication}


Hasil observasi dan wawancara adalah kegiatan permintaan barang masih secara manual, yaitu dengan memberikan daftar barang yang diminta nota dinas dibuat untuk diserahkan ke sapras, setelah itu sapras melakukan pembelian barang. Prosesnya dilaksanakan secara manual, sedangkan Lokasi Penjara Banceuy dan tempat pembelian cukup jauh sehingga prosesnya menyita waktu, dan jika persediaan barang kosong, tentu proses seperti ini dapat menjadi hambatan untuk kinerja dari para staff Penjara Banceuy. Bahkan proses permintaan barang hingga pembuatan nota yang dilakukan masih manual atau menggunakan kertas, sehingga akan sangat boros kertas.

\subsection{Planning}

Untuk jadwal pembuatan Sistem Informasi Akuntansi Persedian Barang Berbasis Web akan dilakukan pada bulan Maret 2021, akan dikumpulkan data selama 3 pekan, lalu pada minggu ketiga bulan Maret 2021 hingga April 2021 akan dilakukan analisis kebutuhan, selanjutnya minggu pertama bulan April sampai minggu terakhir bulan April akan dilakukan desain sistem, lalu di bulan Mei sampai bulan Juni akan dilakukan penerapan sistem dan dilanjutkan oleh pengujian sistem dilakukan sampai bulan Juni, terakhir pada bulan Juni minggu ketiga akan diserahkan sistem kepada user

\subsection{Modelling}

\section{A. Kebutuhan Fungsional}

Kebutuhan Fungsional merupakan kebutuhan yang meliputi proses apa saja yang akan dilakukan oleh sistem. Berikut merupakan kebutuhan-kebutuhan fungsional pada sistem informasi akuntansi persediaan barang:

1. Sistem bisa melakukan add data, view data, dan edit data.

2. Sistem bisa menyetujui proses permintaan barang.

3. Sistem bisa melakukan edit, view, add, dan delete data dari persediaan barang.

\section{B. Kebutuhan Non Fungsional}

Kebutuhan non fungsional ini berhubungan dengan kebutuhan operasional. Kebutuhan operasional sistem informasi akuntansi persedian barang ini antara lain:
1. Sistem hanya akan bisa terakses oleh user yang memiliki Username, Password, dan program telah menyesuaikan level user yang sesuai.

2. Bisa diakses melalui web browser dari PC kantor.

3. Sistem bisa melakukan aktivitas permintaan secara langsung ketika pengguna menginput data barang.

C. Document Flowchart

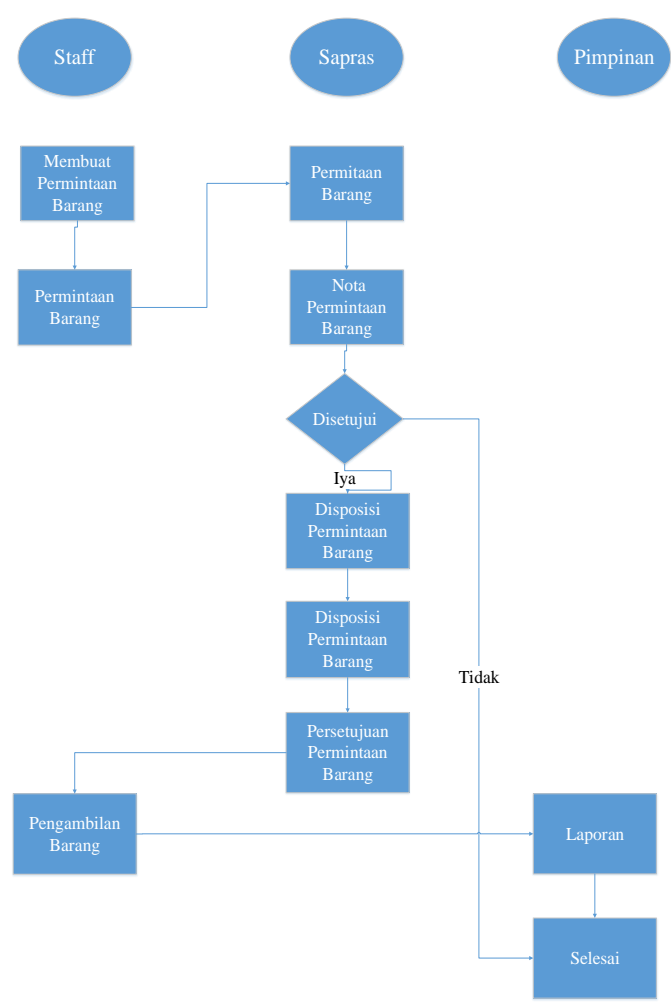

Gambar 3. Document Flowchart

\section{Data Flow Diagram}

Pada gambar 4 dibawah terdapat data flow diagram. Data flow diagram ini menggambarkan seluruh proses yang ada didalam sistem, aliran data utama dari dan menuju sistem, serta entitas eksternal. 


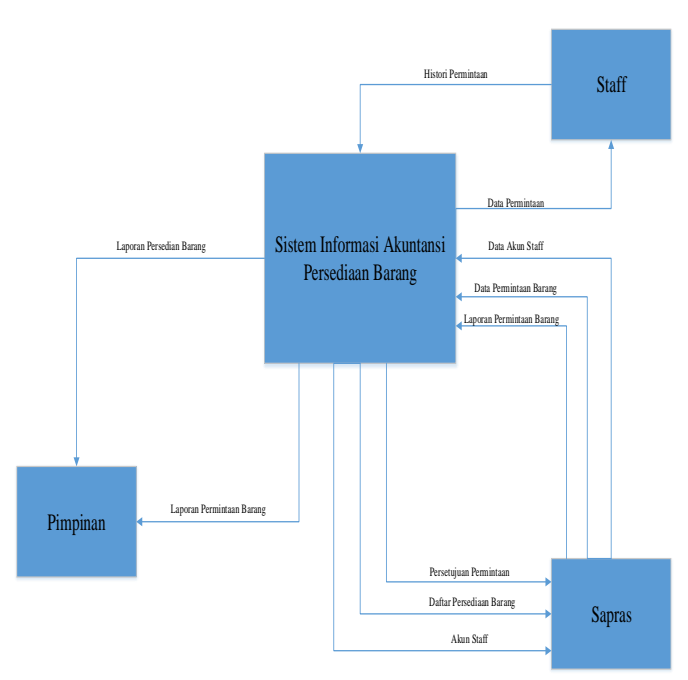

Gambar 4. Data Flow Diagram

\subsection{Construction}

Dari proses perancangan yang telah dilakukan maka hasil dapat dilihat pada gambar dibawah ini:

\section{Halaman Login Staff}

Halaman Login staff bisa diakses apabila staff sudah memiliki akun, setelah memiliki akun staff dapat memasukan id/username dan kata sandi/password untuk masuk.

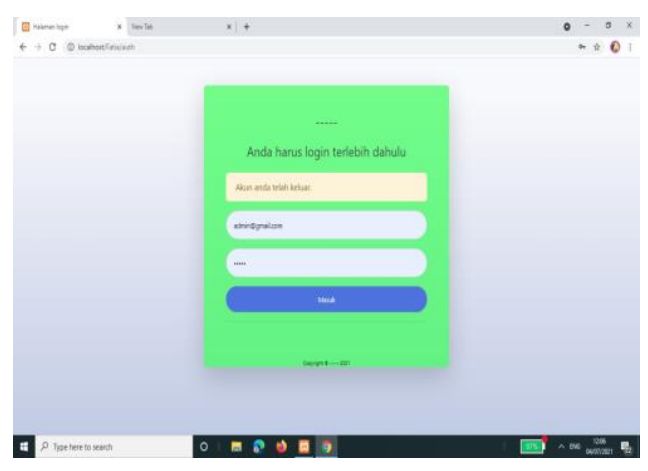

Gambar 5. Halaman Login staff

\section{Halaman Dashboard}

Halaman Dashboard bisa diakses ketika staff sudah berhasil login, pegawai dapat melihat menu barang masuk, barang keluar, dan tabel barang.

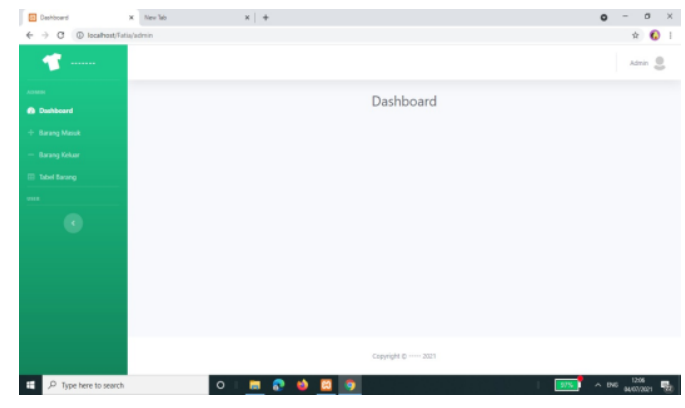

\section{Gambar 6. Halaman Dashboard}

3. Halaman Barang masuk

Halaman barang masuk muncul ketika pegawai memilih menu barang masuk. Pada gambar berikut kami menambah data barang masuk dengan jenis barang ATK kantor dan jumlah barang sebanyak 26 .

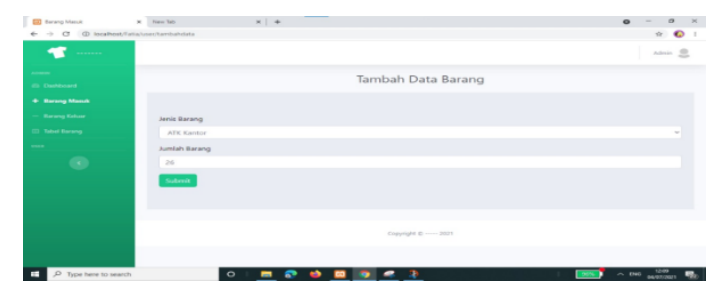

Gambar 7. Halaman Barang Masuk

4. Halaman Tabel Barang

Halaman tabel barang berisi daftar-daftar persediaan barang dan jumlah barang yang tersedia. Pada gambar berikut dapat kita lihat barang yang diinput pada halaman barang masuk sudah terdata di halaman tabel barang yaitu ATK kantor dengan jumlah barang 26.

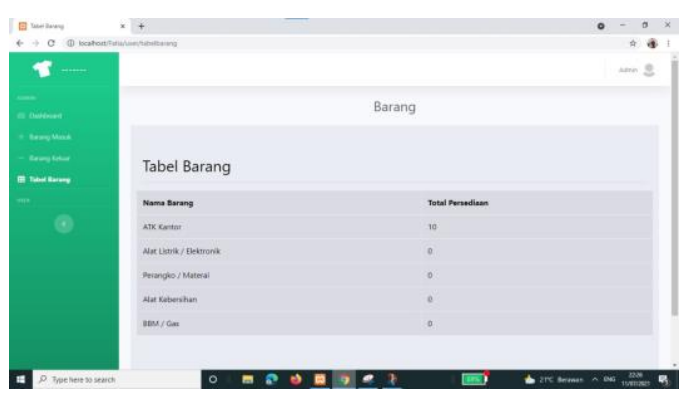

Gambar 8. Halaman Tabel Barang 


\section{Halaman Barang Keluar}

Halaman barang masuk muncul ketika pegawai memilih menu barang masuk. Pada gambar berikut kami menambah data barang keluar dengan jenis barang ATK kantor dan jumlah barang sebanyak 16 .

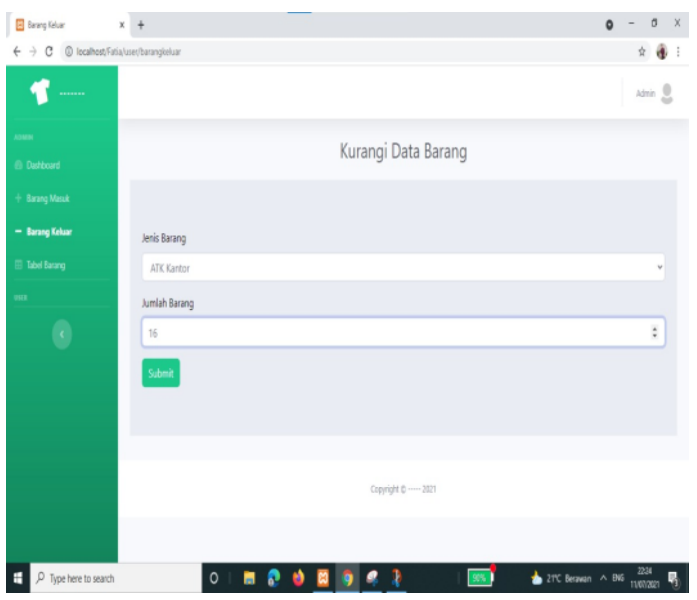

Gambar 9. Halaman Barang Keluar

\section{Halaman Tabel Barang}

Halaman tabel barang berisi daftar-daftar persediaan barang dan jumlah barang yang

tersedia. Pada gambar berikut dapat kita lihat barang yang diinput pada halaman barang keluar sudah terdata di halaman tabel barang yaitu ATK kantor dengan jumlah barang 10.

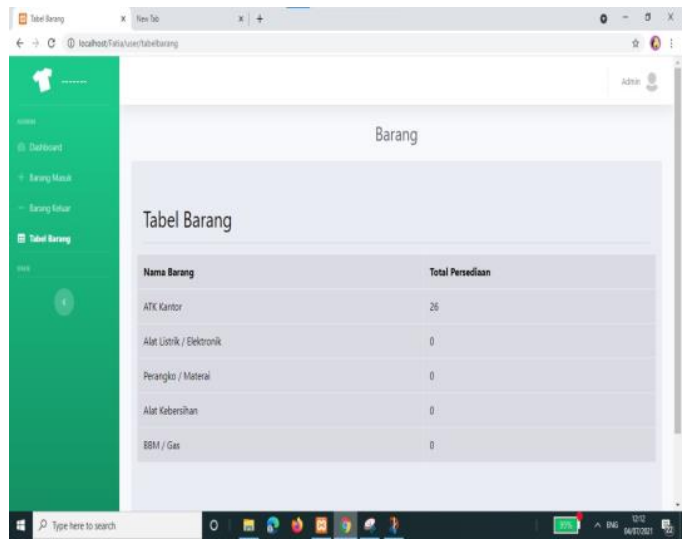

Gambar 10. Tabel Barang Setelah Barang keluar

\subsection{Deployment}

Dalam penyerahan sistem yang sudah dilakukan ke Penjara Banceuy, terdapat saran dari pihak Penjara Banceuy yaitu laporan saat dicetak supaya berupa file pdf, karena laporan yang menggunakan file doc susunan penulisan jadi tidak rapi dan berantakan.

\subsection{Spesifikasi Mininimum Sistem Komputer}

Untuk menjalankan sistem informasi akuntansi ini dibutuhkan spesifikasi minimum tertentu agar sistem informasi akuntansi ini bisa berjalan dengan lancar, spesifikasi minimum tersebut antara lain adalah:

1. Spesifikasi Minimum Software
a. Sistem operasi windows 7
b. Phpmyadmin, penyimpan database MySQL, dan web browser

2. Spesifikasi minimum hardware
a. Processor dengan kecepatan minumum $2 \mathrm{GHz}$
b. RAM minimum DDR3 2GB
c. Harddisk berkapasitas minimum 250GB
d. Monitor beresolusi 1366 x 768
e. Keyboard
f. Mouse
g. Printer untuk mencetak laporan

\section{KESIMPULAN}

Berdasarkan hasil dan pembahasan penciptaan Sistem Informasi Akuntansi Persediaan Barang kesimpulanyadalah sebagai berikut :

1. Metode waterfall digunakan untuk pembuatan sistem yang meliputi tahap communication sampai deployment. PHP digunakan sebagai bahasa pemrograman untuk menciptakan Sistem dan untuk penyimpanan database digunakan MySql.

2. Sistem berhasil menyesaikan permasalahan permintaan barang di Lembaga Permasyarakatan Kelas II A Banceuy Bandung.

3. Pengujian sistem yang digunakan adalah metode blackbox untuk menghasilkan pengujian yang diinginkan, sehingga terpenuhinya kebutuhan fungsional sistem. 


\section{UCAPAN TERIMAKASIH}

Kami ingin mengucapkan terimakasih pada seluruh pihak yang telah membantu dan mendukung dengan sepenuh hati dalam pembuatan jurnal ini sehingga jurnal ini dapat selesai. Tidak lupa kami ucapkan terimakasih pada Lembaga Permasyarakatan Kelas II A Banceuy Bandung yang telah memberikan izin tempat penelitian pada kami serta memberikan data yang dibutuhkan.

\section{DAFTAR PUSTAKA}

[1] Wikipedia, "Penjara Banceuy" 2021. [Online].Available:https://id. wikipedia.org/wiki/Penjara_B anceuy

[2] Usdeldi, Damanik, "Perancangan Sistem Informasi Persediaan Barang Berbasis Web Di PT. Zokkas Sejahtera Jambi, JAAB: Jurnal of Applied Accounting And Bussiness, Vol.2 No. 2 hal 86-93, 2020

[3] T. M. Putra, "Analisis penerapan akuntansi aset tetap pada CV. Kombos Manado.," J. EMBA J. Ris. Ekon. Manajemen, Bisnis dan Akunt, vol. 1, no. 3, pp. 190198, 2013.

[4] Pressman (2012), Rekayasa Perangkat Lunak, Andi Offset, Makassar 